Sharif University of Technology
Scientia Iranica
SCIENTIA
I RAN ICA
http://scientiairanica.sharif.edu

\title{
Assessment of mechanical and durability properties of concrete containing PET waste
}

\author{
R. Saxena ${ }^{a}$, T. Gupta ${ }^{a, *}$, R.K. Sharma ${ }^{a}$, S. Chaudhary ${ }^{b}$, and A. Jain ${ }^{a}$ \\ a. Department of Civil Engineering, CTAE, MPUAT, Udaipur-313001, India. \\ b. Discipline of Civil Engineering, Indian Institute of Technology Indore, Simrol, Indore 453552, India. \\ Received 30 August 2016; received in revised form 17 December 2017; accepted 23 April 2018
}

\section{KEYWORDS \\ PET waste; Static modulus of elasticity; \\ Dynamic modulus of elasticity; \\ Abrasion resistance; \\ Water permeability; \\ Microstructure.}

\begin{abstract}
Plastic waste is a silent threat to the environment and its disposal is a serious issue. To sort out this issue, many efforts have been put to reusing the plastic waste, but no significant results have been achieved. On the contrary, being a widely used construction material, concrete is facing problems due to unavailability of the ingredient materials (sand and coarse aggregate). In this study, polyethylene terephthalate (PET) aggregates manufactured from the waste un-washed PET bottles in shredded form were used to partially replace fine aggregate and coarse aggregate in concrete in various percentages $(0 \%, 5 \%, 10 \%, 15 \%$, and $20 \%)$. Various tests like workability, compressive strength, flexural strength, water permeability, abrasion resistance, and dynamic and static moduli of elasticity were conducted. The micro-structural analysis of the specimens was carried out using an optical microscope. It was found that workability, compressive strength, flexural strength, and dynamic and static moduli of elasticity decreased with the increasing amount of PET waste in concrete. Water permeability of concrete was found to increase with increasing amount of PET waste. In both of the cases, i.e., when fine and coarse aggregates were replaced with PET waste, an improvement in the abrasion resistance of concrete was found.

(C) 2020 Sharif University of Technology. All rights reserved.
\end{abstract}

\section{Introduction}

In the modern lifestyle, the advancement of technology has led to an increase in the amount of waste being generated, resulting in a waste disposal crisis [1]. Plastic is a polymer of hydrocarbon monomers frequently used in everyday life in the form of polythene bags, food packaging material, water bottles, etc. [2-4]. On average, about 10 million plastic bags are discarded

\footnotetext{
*. Corresponding author. Tel.: +919414406223

E-mail addresses: rajat.sxn1991@gmail.com (R. Saxena); guptatrilok@rediffmail.com (T. Gupta);

sharmaraviks@gmail.com (R.K. Sharma);

sandeep.nitjaipur@gmail.com (S. Chaudhary);

abhishekjn11@gmail.com (A. Jain).
}

doi: $10.24200 /$ sci. 2018.20334 every day in the capital city of India $[5,6]$. The world's annual consumption of plastic materials was about 5 million tons in the 1950's, which has now increased to 100 million tons, resulting in more amount of plastic waste generated [7].

The disposal of plastic waste leads to various harmful effects on the environment [8-10]. It leads to poor soil fertility, emission of toxic gases, poor drainage due to landfill, pollution of groundwater due to leaching of chemicals from these waste products, etc. This makes the environment polluted and causes blockages of sewer systems [11].

Since plastic waste has low biodegradability and is present in large quantities, disposal of plastic waste in open environment is considered to be a big problem [12]. Out of the total plastic waste that is generated, the majority of it is not reused and recycled 
as the process requires massive manpower and large processing cost [8].

Recently, many researchers have suggested the utilization of plastic waste in concrete. Utilizing plastic waste in the construction industry has two advantages, namely:

(i) Resolving the environmental problem of the disposal of waste;

(ii) Reduction in construction costs as the waste is available in large quantities at low costs [8].

Concrete is one of the most commonly used construction materials in India because of its high compressive strength, long service life, and low cost $[13,14]$. Concrete requires three essential ingredients, namely cement (the binder), aggregates (ranging in size from fine to coarse), and water $[15,16]$. The constituent materials of concrete are available naturally in all parts of the world [17]. With the increasing requirement for concrete, these materials are getting deficient. It is thus a matter of serious concern for the civil engineers and they are searching for suitable materials which can fully or partially replace these materials [8]. Keeping in view the disposal issues of plastic waste and increasing demand for concrete, its utility in concrete has been studied and investigated by various researchers [18].

Properties of concrete are affected by inclusion of plastic waste. Workability of concrete with plastic waste decreases gradually with increase in plastic waste percentage [6]. Similar observations of decrease in workability have been reported by Kumar et al. [17] who used plastic bags in fiber form to replace cement concrete. However, Ghernouti et al. [19] reported slight improvement in workability with recycled plastic bag waste as replacement of sand in concrete.

Systematic reduction in compressive strength has been observed with the increase in plastic waste content in concrete by some researchers $[6,11,19-21]$.

Borg et al. [22] used PET fibers in concrete and reported that the PET fibers led to a reduction in compressive strength with increasing fiber volume fractions. However, Al-Hadithi and Hilal [23] carried out an experimental study using waste plastic fibers in self-compacting concrete and reported increase in compressive strength with increasing amount of waste plastic.

Flexural strength of plastic concrete is also influenced by the inclusion of plastic waste. It has been reported in the literature that flexural strength decreases with increase in plastic waste content $[11,19,24]$. However, Ramadevi and Manju [21] reported that flexural strength of the specimens containing PET waste increased gradually with increase in the replacement percentage.

Detailed studies have also been carried out for finding the effect of addition of plastic waste on modu- lus of elasticity of concrete and it has been shown that modulus of elasticity decreases with increase in plastic waste content [24-26]. Yang et al. [27] used recycled polypropylene waste in self-compacting concrete to replace sand and reported decrease in elastic modulus with an increase in plastic content. However, Pesic et al. [28] reported slight increase in elastic modulus on using recycled high-density polyethylene plastic fibers in structural concrete.

It is evident from the work reported that although a number of studies are available on utilization of plastic waste in concrete, most of the studies are limited to mechanical properties of concrete containing plastic waste. Effects on properties of concrete like abrasion resistance, water permeability, and dynamic modulus of elasticity have not been reported comprehensively.

In this study, the feasibility of the use of PET waste (plastic waste) in concrete as partial replacement of fine aggregate and coarse aggregate was evaluated. Fine aggregates were replaced by waste plastic from $0 \%$ to $20 \%$ with increments of $5 \%$ in weight. Similarly, coarse aggregates were also replaced by waste plastic from $0 \%$ to $20 \%$ with increments of $5 \%$ in weight. Various properties of waste plastic concrete such as compressive strength, flexural strength, water permeability, abrasion resistant, and static and dynamic moduli of elasticity were evaluated in the laboratory. Micro-structural study was also carried out on these specimens.

\section{Experimental investigation}

\subsection{Materials}

Commonly used Ordinary Portland Cement (OPC) of grade 43 was used for the investigation. The cement used was free from lumps and care was taken to avoid the potential content of moisture while storing. Physical properties of the cement used are shown in Table 1.

The locally available river fine aggregate passing $4.75 \mathrm{~mm}$ sieve as per IS: $383-1970$ [30] was used as fine aggregate in this study. Sieve analysis and specific gravity test were performed using the standard testing procedure. Sieve analysis results are shown in Figure 1. As per the guidelines of IS: 383-1970 [30], the sand belonged to zone II gradation. Specific gravity was observed to be 2.63 .

The coarse aggregate used in this study was procured from the supplier as per IS: 383-1970 [30]. Sieve analysis results of coarse aggregates are shown in Figure 2. Specific gravity of coarse aggregate was observed to be 2.74 .

Waste PET bottles were collected from the local waste supplier in shredded form. PET waste was shredded in two sizes, namely between $0-4.75 \mathrm{~mm}$ for Fine Aggregate (FA) replacement and between 4.75- 
Table 1. Physical properties of cement.

\begin{tabular}{clcl}
\hline \multirow{2}{*}{ Serial no. } & \multicolumn{1}{c}{ Physical property } & $\begin{array}{c}\text { Requirement as per } \\
\text { IS 8112: 2013 [29] }\end{array}$ & Test result \\
\hline 1 & Consistency & - & $32 \%$ \\
2 & Initial setting time & 30 minutes (min.) & $130 \mathrm{~min}$ \\
\multirow{2}{*}{3} & Final setting time & 10 hours (max.) & $213 \mathrm{~min}$ \\
\multirow{2}{*}{4} & Specific gravity & - & 3.13 \\
& 7-day compressive strength & $33 \mathrm{MPa}$ & $34.95 \mathrm{MPa}$ \\
& 28-day compressive strength & $43 \mathrm{MPa}$ & $45.29 \mathrm{MPa}$ \\
\hline
\end{tabular}

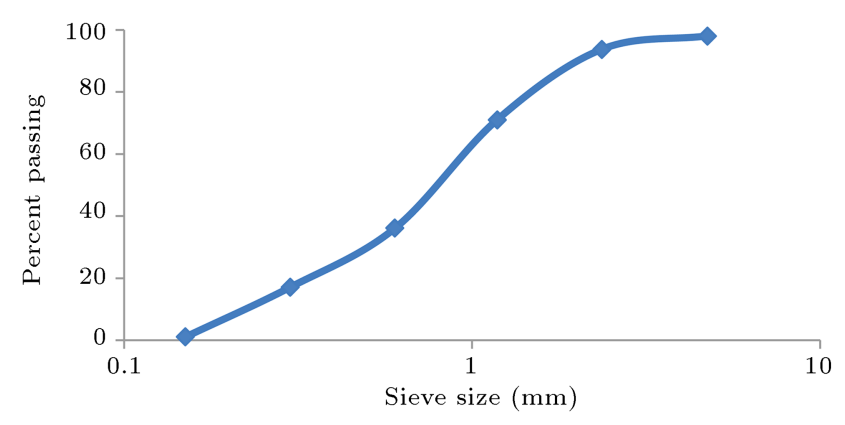

Figure 1. Sieve analysis of fine aggregate.

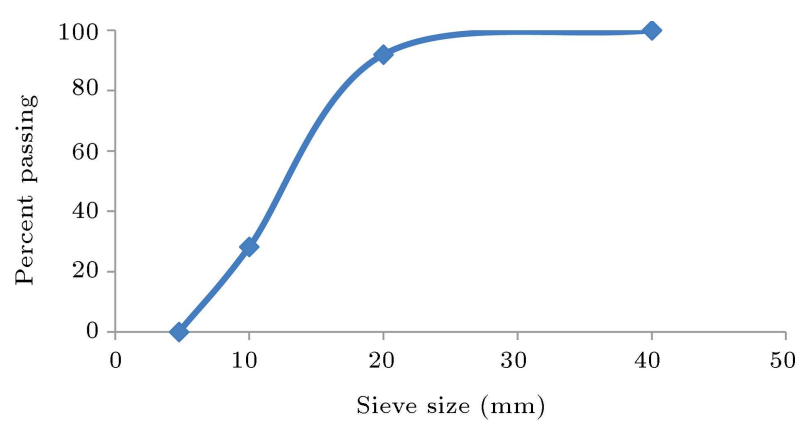

Figure 2. Sieve analysis of coarse aggregate.

$20 \mathrm{~mm}$ for Coarse Aggregate (CA) replacement, as shown in Figures 3 and 4 . It was bought from the same source throughout the study. The waste was not given any special treatment, except sun drying.

\subsection{Mix proportions}

Concrete mix of grade M 25 was designed as per IS:10262 [31] and IS:456 [32]. All materials were mixed with the help of pan type mixer and the PET waste was used in different proportions to partially replace the FA and CA. Details of mix proportion are shown in Table 2.

\subsection{Preparation of specimens}

A total of 180 samples of cubes, 60 samples of beams, and 60 samples of cylinder were cast in this study for various tests (compressive strength, flexural strength, water permeability, abrasion resistance, and static and dynamic moduli of elasticity). During casting, all the specimens were compacted properly using the vibrating table. The specimens were stored in a place, free from vibration, for 24 hours $\pm \frac{1}{2}$ hour from the time of addition of water to the dry ingredients. After this period, the specimens were marked and removed from the moulds, and immediately submerged in clean and fresh curing water.

\section{Results and discussion}

\subsection{Fresh concrete}

Workability of fresh concrete mixes was determined by compacting factor test as per guidelines of IS: 1199-1959 [33]. The variation of compaction factor of concrete is shown in Figure 5. Compaction factor of concrete for $0.45 \mathrm{w} / \mathrm{c}$ ratio without PET waste was found to be 0.91 . The compaction factor was found to decrease with increase in PET waste in concrete. Similar decrease in workability was reported by Kumar et al. [17]. Compaction factor of fresh concrete containing PET waste was observed as 0.91 ,
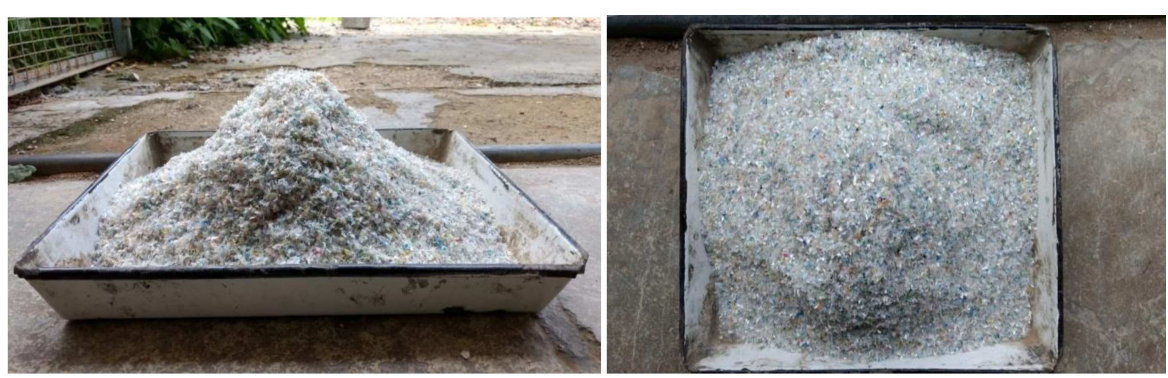

Figure 3. PET waste for fine aggregate replacement. 
Table 2. Concrete mix proportion with PET waste.

\begin{tabular}{cccccc}
\hline Mix no. & Cement & $\begin{array}{c}\text { Fine } \\
\text { aggregate }\end{array}$ & $\begin{array}{c}\text { Coarse } \\
\text { aggregate }\end{array}$ & $\begin{array}{c}\text { PET } \\
\text { waste (\%) }\end{array}$ & $\begin{array}{c}\text { w/c } \\
\text { ratio }\end{array}$ \\
\hline F0 & 1 & 1.54 & 2.76 & 0 & 0.45 \\
F5 & 1 & 1.46 & 2.76 & 5 & 0.45 \\
F10 & 1 & 1.39 & 2.76 & 10 & 0.45 \\
F15 & 1 & 1.31 & 2.76 & 15 & 0.45 \\
F20 & 1 & 1.23 & 2.76 & 20 & 0.45 \\
C5 & 1 & 1.54 & 2.62 & 5 & 0.45 \\
C10 & 1 & 1.54 & 2.48 & 10 & 0.45 \\
C15 & 1 & 1.54 & 2.35 & 15 & 0.45 \\
C20 & 1 & 1.54 & 2.21 & 20 & 0.45 \\
\hline
\end{tabular}
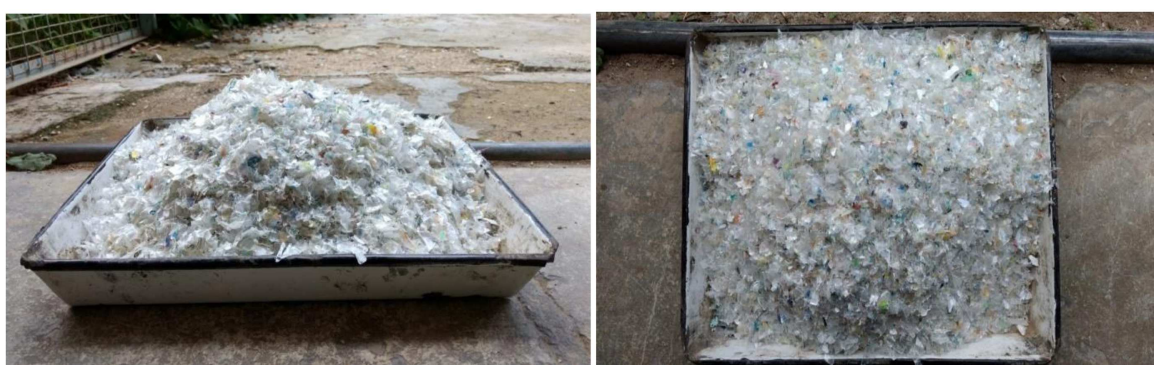

Figure 4. PET waste for coarse aggregate replacement.

$0.83,0.73,0.66$, and 0.61 at $0 \%, 5 \%, 10 \%, 15 \%$, and $20 \%$ replacements of fine aggregate, respectively, and as $0.91,0.81,0.70,0.63$, and 0.56 at $0 \%, 5 \%, 10 \%, 15 \%$, and $20 \%$ replacements of coarse aggregate, respectively. The decrement can be attributed to the fact that particles of PET waste have angular and non-uniform shapes, resulting in less fluidity [34]. Decrement in workability can also be due to the high specific surface area of PET particle compared to sand, which results in more friction between the elements leading to low workability [35].

\subsection{Compressive strength}

This test was performed as per guidelines of IS 516:1959 [36]. Compressive strength of the concrete containing PET waste is shown in Figure 6. Compres-

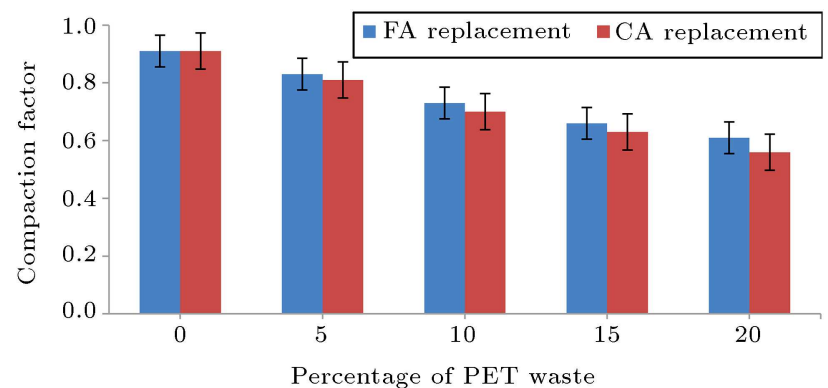

Figure 5. Compaction factor of concrete containing PET waste.

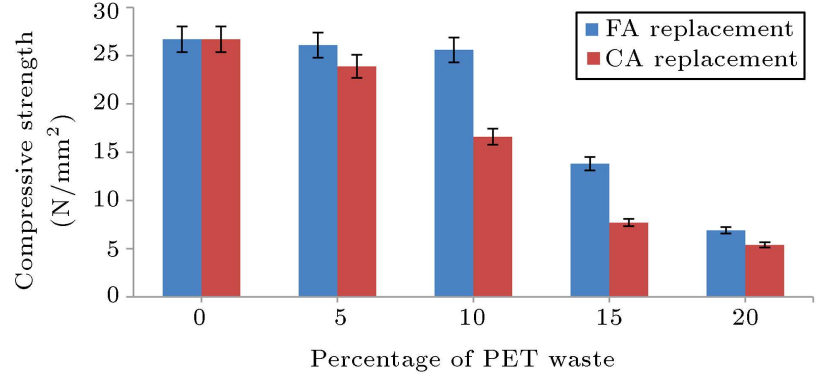

Figure 6. Compressive strength of concrete containing PET waste as fine aggregate and coarse aggregate replacement.

sive strength of concrete without PET waste in 28 days was observed to be $26.7 \mathrm{~N} / \mathrm{mm}^{2}$, which was reduced to $6.9 \mathrm{~N} / \mathrm{mm}^{2}$ at $20 \%$ replacement of fine aggregate by PET waste and to $5.4 \mathrm{~N} / \mathrm{mm}^{2}$ at $20 \%$ replacement of coarse aggregate by PET waste. Reduction in compressive strength due to incorporation of PET waste in concrete was also reported by Borg et al. [22]. The decrease in strength can be attributed to the fact that PET aggregate cannot interact with cement paste and, therefore, the Interfacial Transition Zone (ITZ) in concrete containing PET aggregate is weaker than that in the reference concrete, which results in lower compressive strength [24]. After 10\% inclusion of PET waste in concrete, the sudden decrease in compressive strength can be attributed to the fact 
that PET-aggregate has very low water absorption capacity, which causes more accumulation of water in the transition zone and makes it weaker [37].

\subsection{Flexural strength}

Flexural strength of PET concrete was determined as per guidelines of IS 516:1959 [36] and the test results are shown in Figure 7. Flexural strength of concrete for $0.45 \mathrm{w} / \mathrm{c}$ ratio without PET waste after 28 days of curing was observed to be $3.55 \mathrm{~N} / \mathrm{mm}^{2}$ and it decreased with the increasing amount of PET waste in concrete. Similar observation was reported by Saikia and Brito [24]. Flexural strength of concrete containing PET waste was reduced by $49.6 \%$ at $20 \%$ replacement of fine aggregate and it was reduced by $49 \%$ at $20 \%$ replacement of coarse aggregate. This decrease in strength may be due to decrease in adhesive strength between the surface of waste PET particles and the cement paste, as well as the hydrophobic nature of PET waste, which sometimes limits the hydration of cement [34].

\subsection{Water permeability}

Guidelines of DIN 1048 [38] were followed for determining the depth of water penetration. Figure 8 shows the water permeability test results. Water penetration depth for $0.45 \mathrm{w} / \mathrm{c}$ ratio without PET waste after 28 days of curing was observed to be $24 \mathrm{~mm}$ and it increased with increasing amount of PET waste in concrete; it was observed to be $24 \mathrm{~mm}, 28 \mathrm{~mm}, 42 \mathrm{~mm}$, $71 \mathrm{~mm}$, and $105 \mathrm{~mm}$ at $0 \%, 5 \%, 10 \%, 15 \%$, and $20 \%$ replacements of fine aggregate, respectively. The water

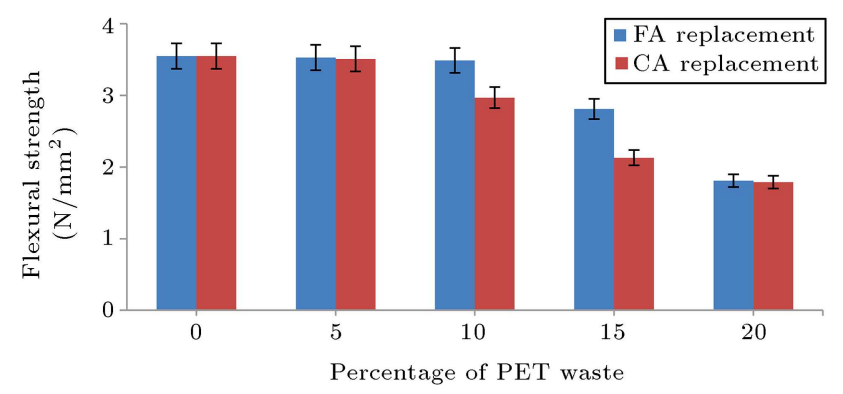

Figure 7. Flexural strength of concrete containing PET waste.

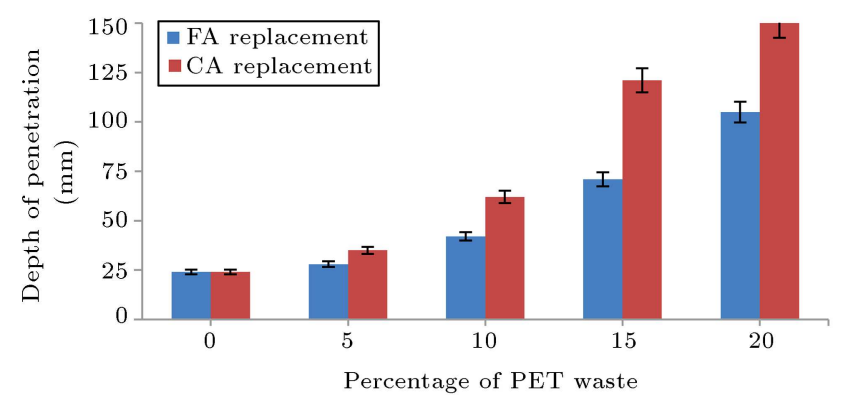

Figure 8. Water penetration depth of concrete containing PET waste. penetration depth was observed to be $24 \mathrm{~mm}, 35 \mathrm{~mm}$, $62 \mathrm{~mm}, 121 \mathrm{~mm}$, and $150 \mathrm{~mm}$ at $0 \%, 5 \%, 10 \%, 15 \%$, and $20 \%$ replacements of coarse aggregate, respectively. This increase in depth of penetration of water can be attributed to the fact that PET waste increases in the ITZ, which can act as a bridge between pores, leading to increase in the number of voids in the structure of concrete. PET waste, due to the irregular shape and less adhesion with cement paste, further increases the number of voids in concrete, resulting in increased water permeability [39].

\subsection{Abrasion resistance}

The abrasion resistance test was performed as per recommended guidelines of IS 1237 [40] and the results are shown in Figure 9. Abrasion resistance was determined in terms of the depth of surface wear. The depth of wear of control concrete was observed to be $0.42 \mathrm{~mm}$ for $0.45 \mathrm{w} / \mathrm{c}$ ratio. With increase in PET waste as replacement of FA and CA, the depth of wear decreased at all replacement levels. Depth of wear was observed to be $0.42 \mathrm{~mm}, 0.38 \mathrm{~mm}, 0.33 \mathrm{~mm}$, $0.32 \mathrm{~mm}$, and $0.27 \mathrm{~mm}$ at $0 \%, 5 \%, 10 \%, 15 \%$, and $20 \%$ replacements of fine aggregate, respectively. Depth of wear was observed to be $0.42 \mathrm{~mm}, 0.31 \mathrm{~mm}, 0.26 \mathrm{~mm}$, $0.25 \mathrm{~mm}$, and $0.23 \mathrm{~mm}$ at $0 \%, 5 \%, 10 \%, 15 \%$, and $20 \%$ replacements of coarse aggregate, respectively. This indicates that resistance to wear increases with increase in the replacement of fine aggregate and coarse aggregate by PET waste. This increase in abrasion resistance can be because $\mathrm{PET}$ waste has good abrasion resistance and high toughness [24].

\subsection{Static modulus of elasticity}

Guidelines of ASTM C469-1994 [41] code were followed for determining the static modulus of elasticity. Test results of static modulus of elasticity for $0.45 \mathrm{w} / \mathrm{c}$ ratio are shown in Figure 10. Static modulus of elasticity without PET waste after 28 days of curing was observed to be $26100 \mathrm{MPa}$ and it decreased with increase in the amount of PET waste. Yang et al. [27] also reported decrease in modulus of elasticity with increase in the amount of PET waste. After 28 days of curing of cylinders containing PET waste, static

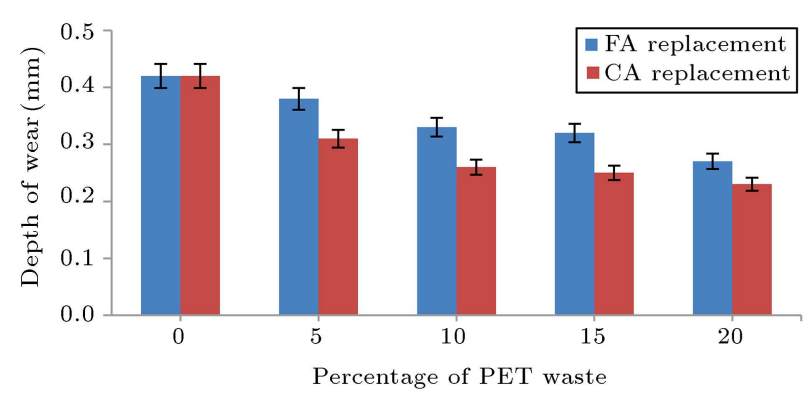

Figure 9. Depth of wear of concrete containing PET waste. 


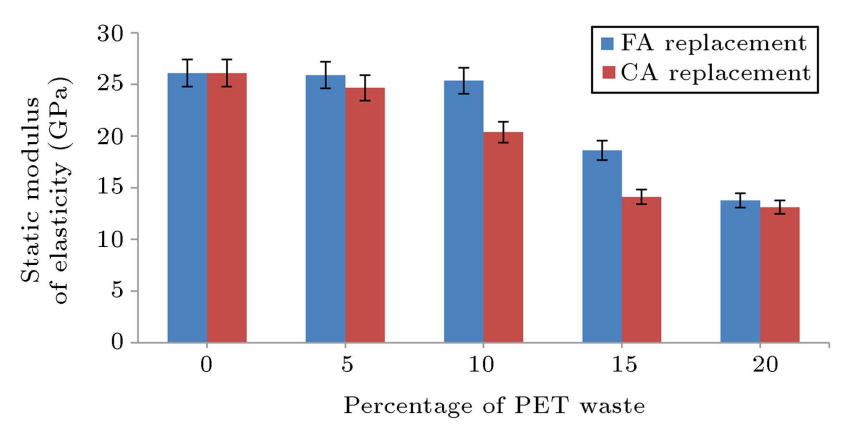

Figure 10. Static modulus of elasticity of concrete containing PET waste.

modulus of elasticity was decreased to $13775 \mathrm{MPa}$ at $20 \%$ replacement of fine aggregate by PET waste. It was decreased to $13121 \mathrm{MPa}$ at $20 \%$ replacement of coarse aggregate by PET waste. The modulus of elasticity of PET is considerably lower than that of natural aggregates; hence, higher PET-aggregate contents lower modulus of elasticity of the resulting concrete [25]. Moreover, the modulus gradually decreases since PET waste is less resistant than natural sand is and it deforms less when an equivalent stress is applied [42].

\subsection{Dynamic modulus of elasticity}

The dynamic modulus of elasticity test was performed as per the guidelines given in the ASTM C597-2009 [43] and the results are shown in Figure 11. Dynamic modulus of elasticity was determined with the help of UPV (ultrasonic pulse velocity) test. Dynamic modulus of elasticity for $0.45 \mathrm{w} / \mathrm{c}$ ratio without PET waste after 28 days of curing was observed to be $52.88 \mathrm{GPa}$ and it decreased as the amount of PET waste increased in concrete. Dynamic modulus of elasticity after 28 days of curing of cubes containing PET waste was reduced to $17.68 \mathrm{GPa}$ at $20 \%$ replacement of fine aggregate by PET waste and it was reduced to $16.04 \mathrm{GPa}$ at $20 \%$ replacement of coarse aggregate by PET waste. Reduction in modulus of elasticity can be attributed to the reduction in composite bulk densities and to plastic aggregates, which decrease the celerity of wave by disturbing the ultrasonic wave propagation [26].

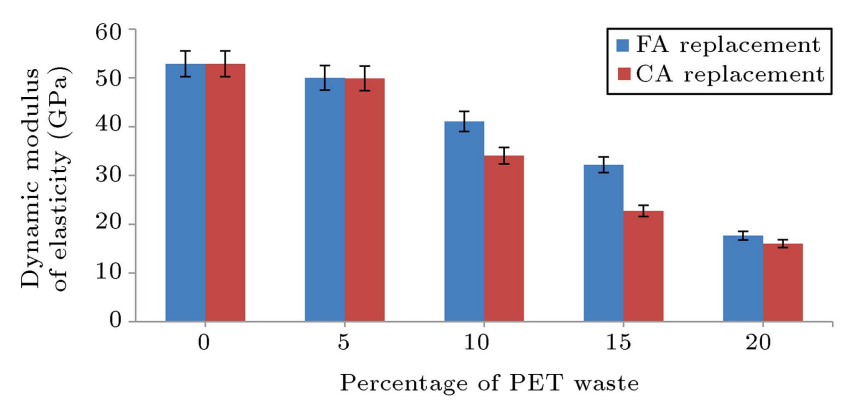

Figure 11. Dynamic modulus of elasticity of concrete containing PET waste.

\subsection{Micro-structural analysis}

The micro-structural analysis of the concrete specimens was carried out using an Optical Microscope (OM) at $90 \times$ magnification. Microscopic images of the plastic concrete specimens (for $0.45 \mathrm{w} / \mathrm{c}$ ratio) containing PET waste as replacement of FA are presented in Figure 12(a)-(d), which show that the PET particles have an irregular shape. Gaps in the interface of PET waste and cement matrix are shown in Figure 12(a) and (b). These gaps reflect weak bond of PET waste with cement mortar. In Figures 12(c) and 12(d), cracks can be observed in the interface of PET waste and cement matrix, which reduce the strength of concrete.

Microscopic images of the plastic concrete specimens (for $0.45 \mathrm{w} / \mathrm{c}$ ratio) containing PET waste as replacement of $\mathrm{CA}$ are presented in Figure 13, which show that the PET particles have an irregular shape. Large gaps or voids in the interface of plastic/cement matrix can be clearly noticed in Figure 13(a)-(d). Figure 13(c) and (d) shows that there is an increase in number of cracks and the size of voids as the amount of PET waste is increased. It indicates that the interfacial bonding between the PET waste and cement paste is very poor, which results in the formation of cracks and reduction in the strength of plastic concrete.

\section{Conclusions}

Based on the experimental results, the following conclusions can be drawn:

- The workability of concrete decreased with increase in the percentage of PET waste in concrete. Compaction factor of fresh concrete containing PET waste decreased from 0.91 to 0.56 ;

- The compressive strength and flexural strength of the concrete containing PET waste decreased with increase in PET waste as replacement of coarse aggregate or fine aggregate. Compressive strength of concrete containing PET waste decreased from $26.7 \mathrm{~N} / \mathrm{mm}^{2}$ to $5.4 \mathrm{~N} / \mathrm{mm}^{2}$ and flexural strength from $3.55 \mathrm{~N} / \mathrm{mm}^{2}$ to $1.79 \mathrm{~N} / \mathrm{mm}^{2}$;

- Water permeability increased when the amount of PET waste was increased in concrete as replacement of coarse or fine aggregate. Water penetration depth increased from $24 \mathrm{~mm}$ to $150 \mathrm{~mm}$;

- Abrasion resistance of concrete increased with increase in the amount of PET waste as replacement of coarse aggregate or fine aggregate. Depth of wear decreased from $0.42 \mathrm{~mm}$ to $0.23 \mathrm{~mm}$;

- Static and dynamic moduli of elasticity of the concrete decreased with increase in the percentage of PET waste in the concrete as replacement of coarse aggregate or fine aggregate. The static modulus of elasticity decreased from $26100 \mathrm{~N} / \mathrm{mm}^{2}$ 


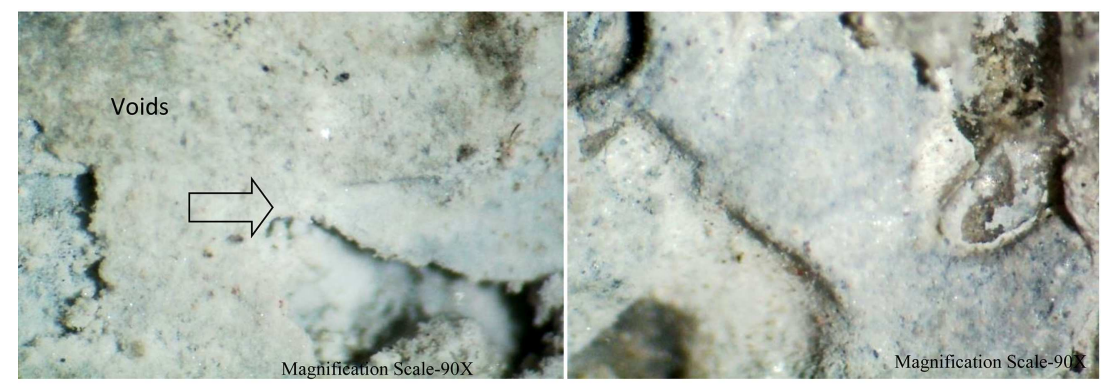

(a) $5 \%$ FA replacement

(b) $10 \%$ FA replacement

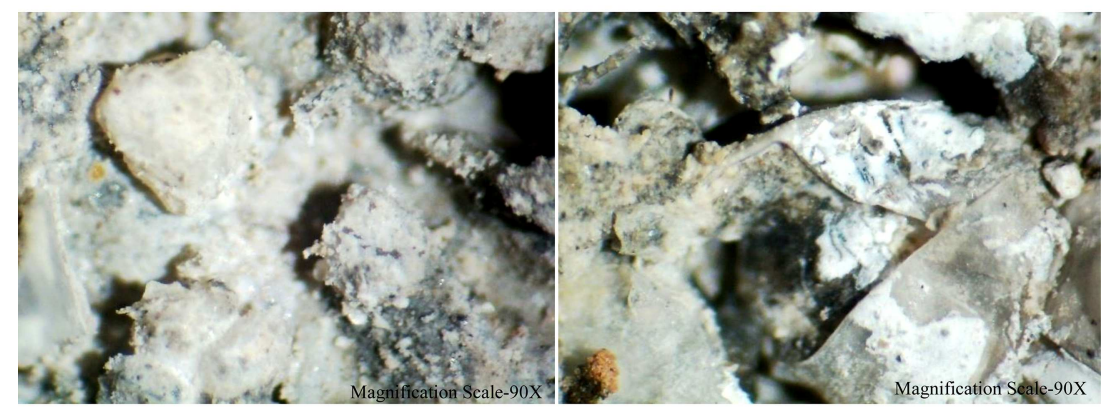

(c) $15 \%$ FA replacement

(d) $20 \%$ FA replacement

Figure 12. Microstructure of concrete containing PET waste as fine aggregate replacement.

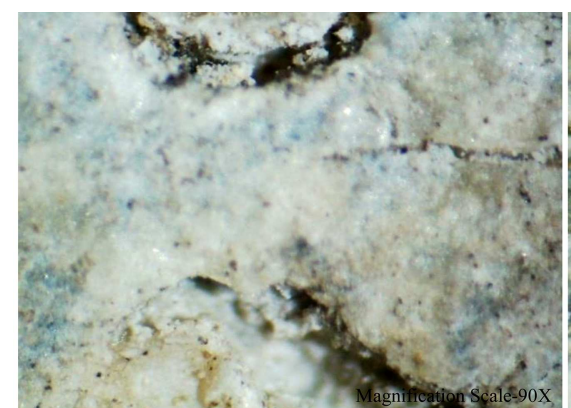

(a) $5 \%$ CA replacement

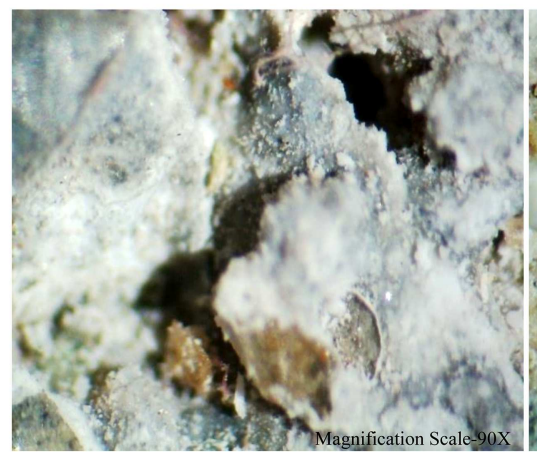

(c) $15 \% \mathrm{CA}$ replacement

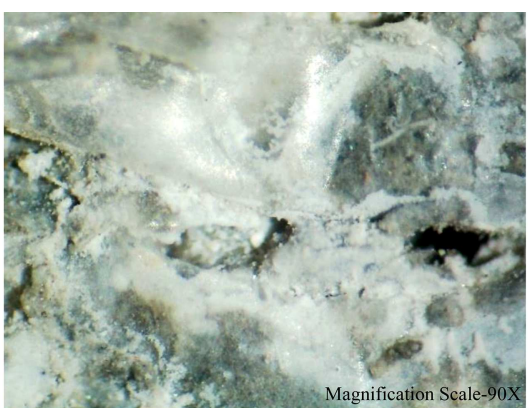

(b) $10 \% \mathrm{CA}$ replacement

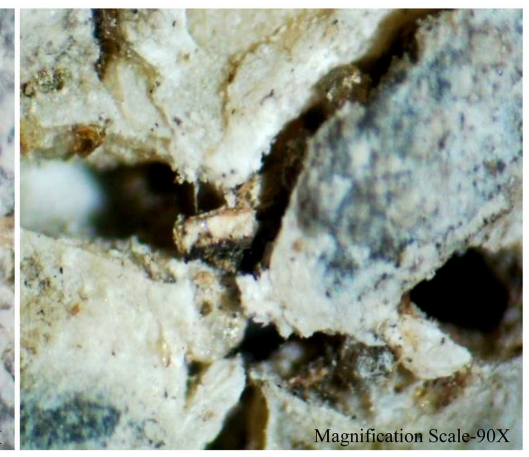

(d) $20 \% \mathrm{CA}$ replacement

Figure 13. Microstructure of concrete containing PET waste as coarse aggregate replacement.

to $13121 \mathrm{~N} / \mathrm{mm}^{2}$ and dynamic modulus of elasticity from $52.88 \mathrm{GPa}$ to $16.04 \mathrm{GPa}$;

- Micro-structural analysis showed weak interfacial bonding between the PET waste and cement paste, which led to voids in the interface and thus, reduced strength of plastic concrete.
Based on various test results, it is concluded that concrete made with PET waste can be used in areas where there is need for more abrasion resistance, like road pavement, and in areas where the strength parameters are not the most important ones. Fine aggregates or coarse aggregates can be partially replaced by up to $5 \%$ PET waste by weight, because at this replacement 
level, most of the properties are within permissible limits.

\section{Acknowledgment}

The authors acknowledge the financial support of this study (No. DST/SSTP/Rajasthan/331) from the Department of Science and Technology, New Delhi.

\section{References}

1. Gupta, T., Sharma, R.K., and Chaudhary S. "Influence of waste tyre fibers on strength, abrasion resistance and carbonation of concrete", Scientia Iranica, 22(4), pp. 1481-1489 (2014).

2. Williams, E.A. and Williams, P.T. "Analysis of products derived from the fast pyrolysis of plastic waste", Journal of Analytical and Applied Pyrolysis, 40, pp. 347-363 (1997).

3. Suganthy, P., Chandrasekar, D., and Kumar, S.P.K. "Utilization of pulverized plastic in cement concrete as fine aggregate", International Journal of Research in Engineering and Technology, 2(6), pp. 1015-1018 (2013).

4. Foti, D. "Use of recycled waste pet bottles fibers for the reinforcement of concrete", Composite Structures, 96, pp. 396-404 (2013).

5. Ruiz-Herrero, J.L., Nieto, D.V., López-Gil, A., Arranz, A., Fernández, A., Lorenzana, A., and RodríguezPérez, M.Á. "Mechanical and thermal performance of concrete and mortar cellular materials containing plastic waste", Construction and Building Materials, 104, pp. 298-310 (2016).

6. Usman, M., Javaid, A., and Panchal, S. "Feasibility of waste polythene bags in concrete", International Journal of Engineering Trends and Technology (IJETT), 23(6), pp. 317-319 (2015).

7. Zhao, R., Torley, P., and Halley, P.J. "Emerging biodegradable materials: starch-and protein-based bionano composites", Journal of Materials Science, $\mathbf{4 3}(9)$, pp. 3058-3071 (2008).

8. Sadiq, M.M. and Khattak, M.R. "Literature review on different plastic waste materials use in concrete", Journal of Emerging Technologies and Innovative Research (JETIR), 2(6), pp. 1800-1803 (2015).

9. Merbouh, M., Glaoui, B., Mazouz, A., and Belhachemi, M. "Use the plastic bag waste in cement concrete", EurAsia Waste Management Symposium, Istanbul, Turkey, 28-30 April 2014, pp. 1-6 (2014).

10. Ghernouti, Y., Rabehi, B., Bouziani, T., Ghezraoui, H., and Makhloufi, A. "Fresh and hardened properties of self-compacting concrete containing plastic bag waste fibers (WFSCC)", Construction and Building Materials, 82, pp. 89-100 (2015).

11. Malak, K.R. "Use of waste plastic in concrete mixture as aggregate replacement", International Journal of Engineering, Education and Technology (ARDIJEET), 3(2), pp. 1-7 (2015).
12. Patil, P.S., Mali, J.R., Tapkire, G.V., and Kumavat, H.R. "Innovative techniques of waste plastic used in concrete mixture", International Journal of Research in Engineering and Technology, 3(9), pp. 29-31 (2014).

13. Gupta, T., Chaudhary, S., and Sharma, R.K. "Assessment of mechanical and durability properties of concrete containing waste rubber tier as fine aggregate", Construction and Building Materials, 73, pp. 562-574 (2014).

14. Bhogayata, A. and Arora, N.K. "Green concrete from the postconsumer plastic wastes: Indian scenario", ICTSET Proceedings, pp. 437-440 (2011).

15. Gupta, T., Sharma, R.K., and Chaudhary, S. "Impact resistance of concrete containing waste rubber fiber and silica fume", International Journal of Impact Engineering, 83, pp. 76-87 (2015).

16. Gupta, T., Chaudhary, S., and Sharma, R.K. "Mechanical and durability properties of waste rubber fiber concrete with and without silica fume", Journal of Cleaner Production, 112, pp. 702-711 (2016).

17. Kumar, A., Srivastava, V., and Kumar, R. "Effect of waste polythene on compressive strength of concrete", Journal of Academia and Industrial Research (JAIR), 3(3), pp. 152-155 (2014).

18. Yesilata, B., Isiker, Y., and Turgut, P. "Thermal insulation enhancement in concretes by adding waste PET and rubber pieces", Construction and Building Materials, 23(5), pp. 1878-1882 (2009).

19. Ghernouti, Y., Rabehi, B., Safi, B., and Chaid, R. "Use of recycled plastic bag waste in the concrete", The International Journal of Scientific Publications: Material, Methods and Technologies, 8, pp. 480-487 (2011).

20. Zerdi, T.A., Yusuf, M., Minhajuddin, M., Waseem, M.F., and Zerdi, M.N. "partial replacement of coarse aggregates with virgin plastics granules (HDPE) in concrete mix", Indian Journal of Applied Research, 6(5), pp. 655-657 (2016).

21. Ramadevi, K. and Manju, R. "Experimental investigation on the properties of concrete with plastic PET (bottle) fibres as fine aggregates", International Journal of Emerging Technology and Advanced Engineering, 2(6), pp. 42-46 (2012).

22. Borg, R.P., Baldacchino, O., and Ferrara, L. "Early age performance and mechanical characteristics of recycled PET fibre reinforced concrete", Construction and Building Materials, 108, pp. 29-47 (2016).

23. Al-Hadithi, A.I. and Hilal, N.N. "The possibility of enhancing some properties of self-compacting concrete by adding waste plastic fibers", Journal of Building Engineering, 8, pp. 20-28 (2016). DOI: http://dx.doi.org/10.1016/j.jobe.2016.06.011

24. Saikia, N. and De Brito, J. "Mechanical properties and abrasion behaviour of concrete containing shredded PET bottle waste as a partial substitution of natural aggregate", Construction and Building Materials, 52, pp. 236-244 (2014). 
25. Kim, S.B., Yi, N.H., Kim, H.Y., Kim, J.H.J., and Song, Y.C. "Material and structural performance evaluation of recycled PET fiber reinforced concrete", Cement and Concrete Composites, 32(3), pp. 232-240 (2010).

26. Marzouk, O.Y., Dheilly, R.M., and Queneudec, M. "Valorization of post-consumer waste plastic in cementitious concrete composites", Waste Management, 27(2), pp. 310-318 (2007).

27. Yang, S., Yue, X., Liu, X., and Tong, Y. "Properties of self-compacting lightweight concrete containing recycled plastic particles", Construction and Building Materials, 84, pp. 444-453 (2015).

28. Pesic, N., Zivanovic, S., Garcia, R., and Papastergiou, P. "Mechanical properties of concrete reinforced with recycled HDPE plastic fibres", Construction and Building Materials, 115, pp. 362-370 (2016).

29. IS 8112, Ordinary Portland Cement, 43 Grade Specification, India (2013).

30. IS 383, Specification for Coarse and Fine Aggregates from Natural Source for Concrete, India (1970).

31. IS 10262, Guidelines for Concrete Mix Proportioning, India (2009).

32. IS 456, Code of Practice-Plain and Reinforced Concrete, India (2000).

33. IS 1199, Methods of Sampling and Analysis of Concrete, India (1959).

34. Ismail, Z.Z. and Al-Hashmi, E.A. "Use of waste plastic in concrete mixture as aggregate replacement", Waste Management, 28(11), pp. 2041-2047 (2008).

35. Rahmani, E., Dehestani, M., Beygi, M.H.A., Allahyari, H., and Nikbin, I.M. "On the mechanical properties of concrete containing waste PET particles", Construction and Building Materials, 47, pp. 1302-1308 (2013).

36. IS 516, Methods of Tests for Strength of Concrete, India (1959).

37. Islam, M.J., Meherier, M.S., and Islam, A.R. "Effects of waste PET as coarse aggregate on the fresh and harden properties of concrete", Construction and Building Materials, 125, pp. 946-951 (2016).

38. DIN 1048, Water Permeability Test (1991).

39. Islam, G.S. and Gupta, S.D. "Evaluating plastic shrinkage and permeability of polypropylene fiber reinforced concrete", International Journal of Sustainable Built Environment, 5(2), pp. 345-354 (2016).

40. IS 1237, Cement Concrete Flooring Tiles-Specification, India (2012).

41. ASTM C469, Standard Test Method for Static Modulus of Elasticity and Poisson's Ratio of Concrete in Compression (1994).\%pagebreak[3]

42. Albano, C., Camacho, N., Hernandez, M., Matheus, A., and Gutierrez, A. "Influence of content and particle size of waste pet bottles on concrete behaviour at different w/c ratios", Waste Management, 29(10), pp. 2707-2716 (2009).

43. ASTM C597, Standard Test Method for Pulse Velocity Through Concrete (2009).

\section{Biographies}

Rajat Saxena completed his MTech in the Department of Civil Engineering, College of Technology and Engineering, MPUAT, Udaipur, India. He received his BSc degree in 2014 from Pacific Institute of Technology (RTU) College, Udaipur. His research interests include durability of concrete and utilization of waste materials in concrete.

Trilok Gupta is an Assistant Professor in the Department of Civil Engineering, College of Technology and Engineering, MPUAT, Udaipur, India. He received his BSc degree in 2001 from Pune University, MSc degree in 2003 from MNIT Jaipur, and PhD in 2016 from Malaviya National Institute of Technology, Jaipur, India. His research interests include durability assessment of engineered concrete mixtures incorporating industrial by-products.

Ravi K. Sharma is a Professor in the Department of Civil Engineering at College of Technology and Engineering, MPUAT, Udaipur, India. He received his BSc degree from MNIT, Jaipur; MSc degree from M.B.M. Engineering College, Jodhpur; and $\mathrm{PhD}$ from Indian Institute of Technology, Delhi, India. His research interests include creep and shrinkage of composite structures and durability of concrete structures.

Sandeep Chaudhary is a Professor of Civil Engineering at IIT Indore, India. Prior to joining IIT Indore, he had been a faculty member of MNIT Jaipur, India, for 20 years. He received his BSc degree from M.B.M. Engineering College, Jodhpur; MSc degree from Malaviya Regional Engineering College, Jaipur; and $\mathrm{PhD}$ from Indian Institute of Technology, Delhi, India. He carried out Post-Doctoral Research at Kunsan National University, Kunsan, South Korea. His research interests include prediction of service load behavior of structures and durability of concrete structures.

Abhishek Jain is pursuing his $\mathrm{PhD}$ program at MNIT Jaipur. He received his BSc degree in 2014 from Sir Padampat Singhania University, Udaipur, India, and his MTech degree in 2016 from the College of Technology and Engineering, MPUAT, Udaipur. His research interests include durability of concrete and utilization of waste materials in concrete. 